\title{
Relationship Between Conical Perspective, Hyperbolic Curves, and Hyperbolic Medicine
}

\author{
Jesús M. González-González
}

\author{
Doctor of Medicine and Surgery (University of Alicante) \\ Specialist in Stomatology (University of Murcia) \\ Practice in a Private Dental Clinic, in Salamanca (Spain)
}

\author{
*Corresponding author details: Jesús M. González-González; gongonjm@@otmail.com
}

\begin{abstract}
"Perspective" is the art of representing objects in such a way that they are visualized from the observer's point of view. Using this technique, a three-dimensional (3D) world is projected onto a two-dimensional (2D) Surface. "Conical perspective" is the one that interests us in hyperbolic medicine since it is the one that most closely approximates the reality we see. We call "hyperbolic medicine" (abbreviated "Medipérbola") to the study of hyperbolic curves that occur in the physiology of a living being, especially in humans, about other hyperbolic curves that may be in nature, such as electromagnetic fields, expansion-contraction systems in motion, circadian rhythms, and space-time relativity. We think that when we observe an object, the conical perspective of that image is not parallel lines that converge at a point, but hyperbolic curves of space-time, and the hyperbolic curves that occur in human physiology would be related to them. The relationships between conic perspective, hyperbolic curves of space-time, and hyperbolic curves of human physiology have been studied. Conclusions: 1 . Conic perspective represents images that travel at the speed of light to the eye of the observer, following hyperbolic curves of space-time. 2. Human vision is hyperbolic because the space in which we live is deformed by "hyperbolic curves", which exist in any longitude and latitude of the earth's geography. 3. Human physiology can be conditioned by these hyperbolic curves, to adapt to this hyperbolic deformation of the space in which we live.
\end{abstract}

Keywords: perspective; conical; hyperbolic; medicine; space; time; physiology; human; relativity

\section{INTRODUCTION \\ PERSPECTIVE is the art of representing objects in such a way that they are visualized from the observer's point of view. Using this technique, a three-dimensional (3D) world is projected onto a two-dimensional (2D) surface. Perspective helps us create a sense of depth, giving an effect of volume to objects [1]. The eye estimates the distance based on the decrease in the size of the objects and the angle of convergence of the lines (linear perspective) [1]. The visual cone is the set of visual rays that leave the observer's eye towards an object and in humans, it has an amplitude of about $60^{\circ}$ [2]. There are many types of perspectives, but we can group them into two:}

- Conical perspective (linear, central)

this is the one that interests us in hyperbolic medicine since it is the one that most closely approximates the reality we see. Objects get smaller as their distance from the observer increases. The parallel lines of the model converge at some point in the representation. What we see forms a conical beam, with its vertex in the point of view. This is the one that is closest to the real vision of the human being [3]. Photographs produce these types of perspectives by picking up the projected image [2-7]. In a street, the objects become smaller as they move away from the observer's point of view (fig. 1).

- Axonometric perspective (parallel)

This type of perspective is unimportant in hyperbolic medicine, as it is a non-real representation. The volumes represented retain their dimensions in each of the three directions of space. Objects do not reduce in size as they move away from the observer. There is no point where the lines in the drawing converge. The parallel lines of reality are also parallel in representation $[3,4]$.

A HYPERBOLIC CURVE is an open geometric figure with two branches, obtained by cutting a right cone in a plane oblique to the axis of symmetry. The plane does not have to be parallel to the axis of the cone and the hyperbola will be symmetric in any case [8] (fig. 2).

We call "HYPERBOLIC MEDICINE" (abbreviated "Medipérbola") to the study of hyperbolic curves that occur in the physiology of a living being, especially in humans, about other hyperbolic curves that may be in nature, such as electromagnetic fields, expansion-contraction systems in motion, circadian rhythms, and space-time relativity. It has been described that the human eye perceives the space around us as a hyperbola [9]. In figure 1, the image of each object is translated to the human eye at the speed of light. According to previous works, the trajectory of this image to the observer's eye does not go in a straight line, but through curved lines [9-14]. These works conclude that the images of nature are hyperbolas because the deformed space in which we live is hyperbolic. (fig. 3).

Space-time relativity, perpendicular to the axis of motion of an organ, has also been described. According to the Theory of Relativity an object that moves on an X-axis, perpendicular to the line of sight of an observer, contracts 
that length $\mathrm{X}$ and its time is dilated, while its dimensions $\mathrm{Y}$ and $Z$, perpendicular to that direction of movement, are not altered $[15,16]$. According to current works, it is different if that object moves perpendicular to the line of sight of an observer, or if it approaches or moves away in the same line of sight [10-14]. These works indicate that when the object approaches an observer in the same line of sight, he perceives its height $(\mathrm{Y})$ and its width $(\mathrm{Z})$ increasing in size. For that reason, he interprets that those dimensions $\mathrm{Y}$ and $\mathrm{Z}$, perpendicular to the axis of movement of the object, have been dilated. If the object moves away from the observer along the same line of sight, he perceives those dimensions $\mathrm{Y}$ and $\mathrm{Z}$, perpendicular to the movement, each time smaller, for which he interprets that there is a contraction [10-14] (table 1) (fig. 4). In both cases, the observer perceives hyperbolic images, when the organ approaches or when it moves away.

We think that when we observe an object, the conical perspective of that image is not parallel lines that converge at a point, but hyperbolic curves of space-time, and the hyperbolic curves that occur in human physiology would be related to them. The objective of this work is to demonstrate the relationship that exists between conical perspective, hyperbolic curves, and hyperbolic medicine.

\section{MATERIAL AND METHODS}

In Internet search engines and various databases (Medline, Scielo) a bibliographic review of scientific works about conical perspective, hyperbolic curves in medicine and space-time perpendicular to the movement of an organ has been made. Then, the relationships between conic perspective, hyperbolic curves of space-time, and hyperbolic curves of human physiology have been studied.

\section{RESULTS}

(1) The conical perspective is the one that is closest to the real vision of the human being and forms a conical bundle of parallel lines that converge at some point in the representation (fig. 1) [1-7].

(2) Numerous works relate human vision to images of hyperbolic curves [10-14,31,32] (Figures 2, 3, and 4).

(3) There is space-time relativity, perpendicular to the axis of movement of an organ, which gives hyperbolic curves [10-14] (table 1).

(4) Images in nature are "hyperbolas" and exist independently of the longitude and latitude of the Earth where they are observed [33].

(5) In human physiology, hyperbolic curves are very frequent (Table 2) [9-11,17-30] and can be influenced by hyperbolic curves.

\section{DISCUSSION}

The conical perspective has been widely studied in the Art, to represent three-dimensional images (3D), in a twodimensional plane (2D). In a painting, the artists draw straight lines that converge at some point, to make a representation similar to the real one. However, this is somewhat fictitious. The image that reaches the observer's eyes does so at the speed of light. Then, the components of space and time would have to be taken into account. We know from previous work that, at different longitudes and latitudes of the Earth, images of cities can be seen in a conical perspective [33]. A conical perspective image is a static image. It is a snapshot image. When we see that moving image, the lines turn into curves and we see a hyperbola. The conic perspectives are hyperbolic spacetime curves (Figures 3 and 4).
In previous works, it has been described that geomagnetic rhythms can act as a time clock to organize physiological rhythms. This means that human biorhythms follow hyperbolic curves. Cellular physiological processes are subject to permanent synchronization [32]. There is a close interaction between geomagnetic and biomagnetic fields throughout evolution [31,32,34-39].

The results obtained indicate that hyperbolic curves are very common in medicine and are found in many human physiological processes [17-30]. It is possible to think that human physiology is conditioned by that deformed space in which we live. In this way, the hyperbolic curves that we see in medicine could be related to this hyperbolic deformation. Some hyperbolic curves that occur in human physiology can be conditioned by the general hyperbolic deformation of the space in which we live.

\section{CONCLUSIONS}

(1) Conic perspective represents images that travel at the speed of light to the eye of the observer, following hyperbolic curves of space-time.

(2) Human vision is hyperbolic because the space in which we live is deformed by "hyperbolic curves", which exist in any longitude and latitude of the earth's geography.

(3) Human physiology can be conditioned by these hyperbolic curves, to adapt to this hyperbolic deformation of the space in which we live.

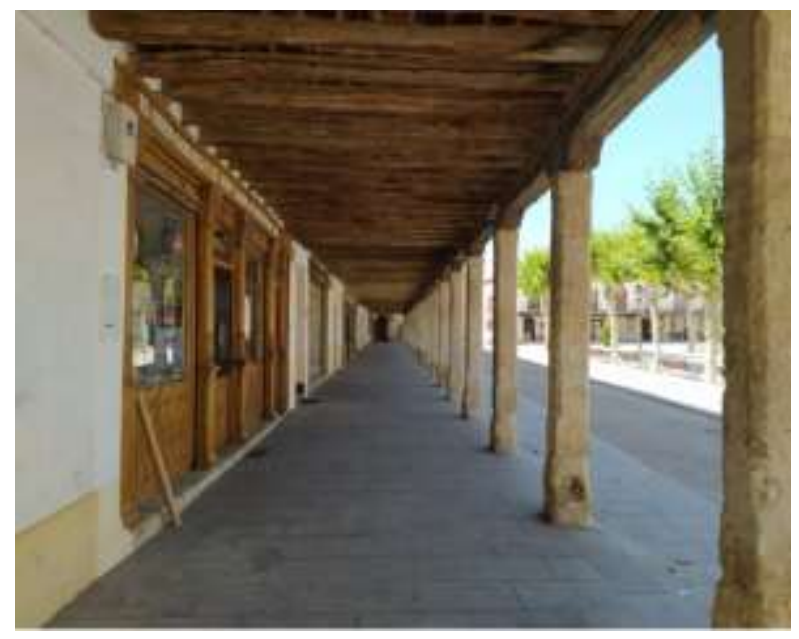

FIGURE 1: Conical perspective on a street in Fuentesauco (Spain)

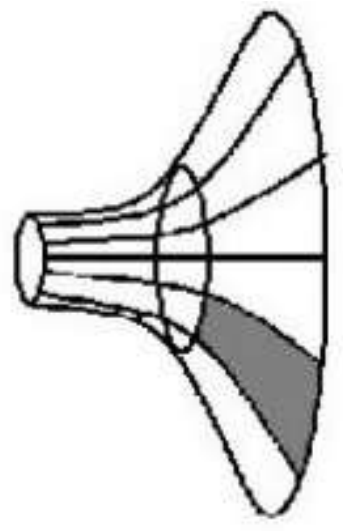

FIGURE 2: Hyperbolic image. 

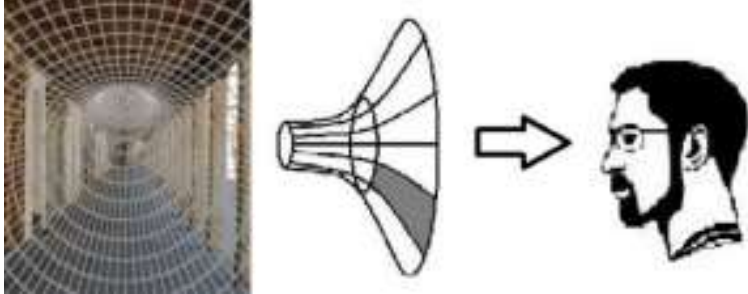

FIGURE 3: Objects further away from the observer are smaller for him because he sees a hyperbolic image

TABLE 1: The classical Theory of Relativity and the results of a previous study by the author

\begin{tabular}{|c|c|}
\hline \multirow{2}{*}{$\begin{array}{l}\text { Classical theory of } \\
\text { Redativity. Object } \\
\text { moves perpendicular to } \\
\text { the obsenver's ine of } \\
\text { sigle }\end{array}$} & $\begin{array}{l}\text { Length } X \text { paralled to the axis of movement contracts by a } \\
\text { factor } K=\sqrt{1-v^{2} / c^{2}}\end{array}$ \\
\hline & $\begin{array}{l}\text { Time ts poralld to the axis of movement dilates by a } \\
\text { factor } \mathrm{K}=\frac{1}{\sqrt{1-x^{2} / e^{2}}}\end{array}$ \\
\hline \multirow{2}{*}{$\begin{array}{l}\text { Results of a previous } \\
\text { stady by the anthor } \\
\text { Object approaches of } \\
\text { moves away from the } \\
\text { observer in his same } \\
\text { line of sigts }\end{array}$} & $\begin{array}{l}\text { Lengtis } \mathrm{Y} \text { and } \mathrm{Z} \text { perpendicular to the axis of movement: } \\
\text { - When the organ approaches the observer these lengths } \\
\text { dilate by a factor } \mathrm{K}=\frac{1}{\sqrt{1-v^{2} / \mathrm{e}^{2}}} \\
\text { - When the organ moves away from the observer these } \\
\text { lengths coetract by a factor } \mathrm{K}=\sqrt{1-\mathrm{v}^{2} / \mathrm{c}^{2}}\end{array}$ \\
\hline & $\begin{array}{l}\text { Times } t \text {, and } t, \text { perpend cular to the axis of movement: } \\
\text { - When the organ approaches the observer these times } \\
\text { contract by a factor } \mathrm{K}=\sqrt{1 \cdot \mathrm{v}^{2} / \mathrm{c}^{2}} \\
\text { - When the organ moves away from the observer these } \\
\text { times dilate by a factor } \mathrm{K}=\frac{1}{\sqrt{\mathrm{t} \cdot \mathrm{F}^{1 / 2}}}\end{array}$ \\
\hline
\end{tabular}

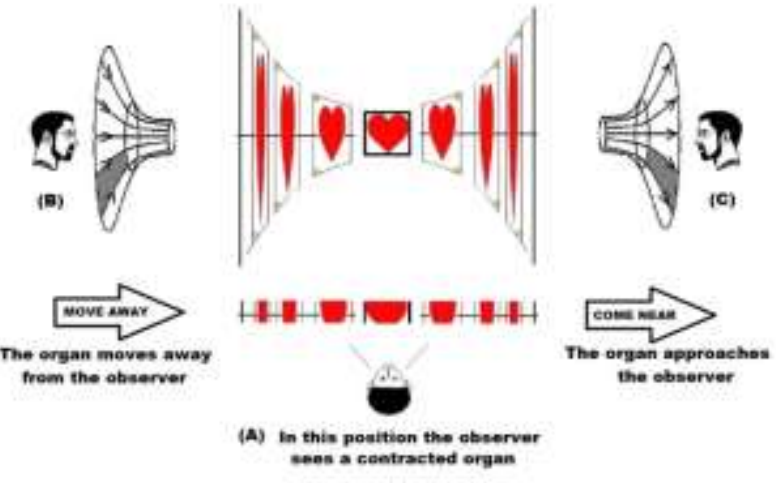

FIGURE 4: When an organ moves perpendicular to the observer's line of sight, he sees it contracted (A). If the organ is moving parallel to its line of sight, the observer sees a hyperbola moving away (B) or approaching (C)

TABLE 2: Some hyperbolic curves in physiology

- Oxygen saturation for hemoglobin and myoglobin about
partial oxygen pressure
- Aspartate saturation curves
- Insulin sensitivity in oral glucose tolerance test
- Sometimes dose-effect relationship curves
- Glucokinase and fructokinase saturation curves
- Heart rate responses during exercise
- Strength-speed ratio of myocardial myosin isoenzymes
- Force-speed ratio of shortening of skeletal muscle fibers
- In aviation, periods of incapacitation in extreme gravitational
stress
- Descriptions of the perception of odors, in an olfactory space
- The human eye perceives a hyperbolic image of reality

\section{REFERENCES}

[1] López Vílchez, I., García López, R.M., Posse, P. (1992) Perspectiva: Ciencia y Magia de la representación. Junta Andalucía. Consejería de Innovación, Ciencia y Empresa. Granada.
[2] Hernando Pérez, J. La Perspectiva Cónica en la Colección de la Escuela Barroca Española del Museo del Prado. Accessed September 13, 2020 at https://content.cdnprado.net/doclinks/pdf/aprende /educacion/fp/i-encuentro/jesus-hernado-perez.pdf

[3] Bartolomé Ramírez, R. (2011). Perspectiva: fundamentos y aplicaciones. Axonométrico, caballera, cónica. Material didáctico ingenierías, no 17 . La Rioja: Servicio de publicaciones. Universidad de la Rioja.

[4] Anonymous. Perspectiva. Accessed September 13 2020 at https://es.wikipedia.org/wiki/Perspectiva

[5] Beltrán Polaina, J.M. (2006). Estudio de la perspectiva cónica mediante la conjunción del espacio real y el proyectado utilizando la imagen digital. Tesis doctoral. Universidad de Bellas Artes. Granada: Editorial de la Universidad de Granada.

[6] Salvador Giménez, M.A. (2015). Introducción a los sistemas de representación lineal: perspectiva cónica. Master en profesorado de educación secundaria obligatoria y bachillerato, formación profesional y enseñanza de idiomas. Trabajo fin de Master. Almería: Universidad de Almería.

[7] Anonymous. Perspectiva cónica. Accessed September 13,2020 at

https://es.wikipedia.org/wiki/Perspectiva_c\%C3\%B 3nica

[8] Chambadal, L. (1984). Diccionario de matemáticas. Barcelona: Ediciones Grijalbo, S.A.

[9] Gómez Argelles, J. (2016). Cuando las rectas se vuelven curvas. Las geometrías no euclídeas. Barcelona: Ed. RBA Coleccionables.

[10] González-González, JM. (2020). Hyperbolic curves in Medicine and the Earth's magnetic field. International Journal of Science and Research (IJSR), 9 (3), 16201624.

[11] González-González, JM. (2020). Hyperbolic Medicine. A Space-Time Synchronization External to the Human. International Journal of Science and Research (IJSR), 9 (11), 234-239.

[12] González-González, JM. (2017). Teleportation of human and their organs in the treatment of cancer. International Journal of Current Research, 9 (6), 52659-52663.

[13] González-González, JM. (2017). Teleportation of human organs in the treatment of diseases, hyperbolic spaces and unified fields. International Journal of Current Research, 9 (9), 57340-57342.

[14] González-González, JM. (2019). Physical Theory of Premonition in Medicine. International Journal of Science and Research (IJSR), 8 (5), 1340-1344.

[15] Resnick, R. (1981). Introducción a la teoría especial de la relatividad. Mexico: editorial Limusa.

[16] Andreu Tormo, J. (1978). La relatividad descifrada. Valencia: Industrias Gráficas ECIR.

[17] Akitoshi Seiyama. (2006). Virtual cooperativity in myoglobin oxygen saturation curve in skeletal muscle in vivo. Dynamic Medicine, 5, 3. 
[18] Melvin Khee-Shing Leow. (2007). Configuration of the hemoglobin oxygen dissociation curve demystified: a basic mathematical proof for medical and biological sciences undergraduates. Adv Physiol Educ. 31, 198201.

[19] Werner Müller-Esterl. (2008). Bioquímica. Fundamentos para Medicina y Ciencias de la Vida. Barcelona: Editorial Reverte.

[20] Atassi, MZ., Childress C. (2005). Oxygen-binding heme complexes of peptides designed to mimic the heme environment of myoglobin and hemoglobin. Protein J, 24 (1), 37-49.

[21] Tallarida, RJ. (2016). Drug Combinations: Tests and Analysis with Isoboles. Curr Protoc Pharmacol, 72, 919.

[22] Doelle, HW. (1982). Kinetic characteristics and regulatory mechanisms of glucokinase and fructokinase from Zymomonas mobilis. European J Appl Microbiol Biotechnol, 14, 241-246.

[23] Vickrey. JF., Herve, G., Evans, DR. (2002). Pseudomonas aeruginosa Aspartate

Transcarbamoylase. Characterization of its catalytic and regulatory properties. The journal of biological chemistry, 277 (27), 24490-24498.

[24] Utzschneider, KM., Prigeon RL., Carr, DB., et al. (2006). Impact of Differences in Fasting Glucose and Glucose Tolerance on the Hyperbolic Relationship Between Insulin Sensitivity and Insulin Responses. Diabetes Car, 29, 356-362.

[25] Retnakaran, R., Shen, S., Hanley, AJ., Vuksan, V., Hamilton, JK., Zinman, B. (2008). Hyperbolic Relationship Between Insulin Secretion and Sensitivity on Oral Glucose Tolerance Test. Obesity, 16, 1901-1907.

[26] Mizu, J., Nakatsu, T., Murakami, T., et al. (2000). Exponential hyperbolic sine function fitting of heart rate response to constant load exercise. Jpn J Physiol, 50 (4), 405-12.

[27] Seiryo Sugiura, Hiroshi Yamashita, Masataka Sata, et al. (1995). Force-velocity relations of rat cardiac myosin isozymes sliding on algal cell actin cables in vitro. Biochimica et Biophysics Acta, 1231, 69-75.
[28] Iwamoto, H., Sugaya, R., Sugi, H. (1990). Forcevelocity relation of frog skeletal muscle fibres shortening under continuously changing load. Journal of Physiology, 422: 185-202.

[29] Whinnery, T., Forster, EM., Rogers, PB. (2014). The $+\mathrm{Gz}$ recovery of consciousness curve. Extreme Physiology \& Medicine, 3, 9.

[30] Zhou, Y., Smith, BH., Sharpee, TO. (2018). Hyperbolic geometry of the olfactory space. Sci. Adv, 4 (8), eaaq1458.

[31] González-González, JM. (2018). Circadian rhythms and dental caries. International Journal of Current Research, 10 (7), 71616-71618.

[32] González-González, JM. (2020). Psychological and physiological time, in childhood and old age. Synchronization with the Earth's hyperbolic magnetic field. EAS J Med Surg, 2 (6), 140-145.

[33] González-González JM. (2021). Hyperbolic Medicine: General and Local Hyperbolic Curves on Earth, Influencing Human Physiology. International Journal of Scientific Advances, 2 (4), 630-635. DOI: $10.51542 /$ ijscia.v2i4.29

[34] Valentinuzzi, ME. (2004). Magnetobiology: a historical view. IEEE Eng Med Biol Mag, 23 (3), 85-94.

[35] Sachiko Yamaguchi-Sekino, Masaki Sekino, Shoogo Ueno. (2011). Biological effects of electromagnetic fields and recently updated safety guidelines for strong static magnetic fields. Magn Reson Med Sci, 10 (1), 1-10.

[36] Richard H W Funk, Thomas Monsees, Nurdan Ozkucur. (2009). Electromagnetic effects - From cell biology to medicine. Prog Histochem Cytochem, 43 (4), 177-264

[37] Zannella, S. Biological effects of magnetic fields. Accessed September 13, 2020 at https://cds.cern.ch/record/1246526/files/p375.pdf

[38] Barcia Salorio, D. (2007). Ritmos biológicos y periodicidad en psiquiatría. Murcia: Cuaderna editorial.

[39] Rojo Sierra, M. (1984). La asimetría cerebral y la experiencia psicológica y patológica del tiempo. Valencia: Sancho Artes Gráficas. 